\title{
PENGARUH GAYA KEPEMIMPINAN KEPALA RUANGAN TERHADAP KINERJA PERAWAT PELAKSANA DI RUANG RAWAT INAP RSUD DR. SLAMET GARUT
}

\author{
Andhika Lungguh Perceka ${ }^{1}$
}

\begin{abstract}
Abstrak
Perawat sebagai salah satu tenaga kesehatan memegang peranan penting dalam upaya mencapai pembangunan kesehatan. Dalam mencapai kualitas pelayanan yang baik kepala ruangan memberikan peran penting dalam mengelola asuhan keperawatan. Peran kepala ruangan sebagai manajer mampu merencanakan segala aktivitas yang dilakanakan oleh perawat, membuat pembagian kerja, memberikan arahan kerja, pengawasan dan evaluasi kerja. Hal ini dipengaruhi oleh gaya kepemimpinan kepala ruangan dalam memimpin anggotanya agar tujuan dari organisasi dapat tercapai. Metode penelitian ini menggunakan deskriptif korelasi dengan pendekatan cross sectional. Variabel terdiri dari gaya kepemimpinan kepala ruangan dan kinerja perawat pelaksana. Populasi seluruh perawat rawat inap sebanyak 296 orang. Metode pengambilan sampel yaitu dengan menggunakan propotional stratified random sampling dengan diperoleh sampel sebanyak 74 orang. Hasil penelitian menunjukan bahwa gaya kepemimpinan kepala ruangan mayoritas bergaya kepemimpinan demokratis sebanyak 42 orang (56.8\%). Kinerja perawat pelaksana mayoritas berkinerja kurang baik sebanyak 39 orang $(52.7 \%)$. Analisa bivariat menggunakan chi square. Hasil penelitian menunjukan ( $\mathrm{p}$ value $=0.731$ ). kesimpulan : tidak ada pengaruh antara gaya kepemimpinan kepala ruangan terhadap kinerja perawat pelaksana di Rumah Sakit Umum dr. Slamet Garut.
\end{abstract}

Kata kunci : Gaya Kepemimpinan, Kepala Ruangan, Kinerja Perawat Pelaksana

\begin{abstract}
Nurses as one health worker plays an important role in efforts to achieve health development. In achieving good service quality the head of the room provides an important role in managing nursing care. The role of the head of the room as a manager is able to plan all activities undertaken by nurses, making the division of labor, provide direction of work, supervision and evaluation work. This is influenced by the leadership style of the head of the room in leading its members so that the goals of the organization can be achieved. This research method using descriptive correlation with cross sectional approach. The variables consist of the headroom leadership style and the performance of the implementing nurse. The population of all inpatient nurses was 296 people. Sampling method that is by using propotional stratified random sampling with obtained sample counted 74 people. The result of the research shows that leadership style of head of majority room with democratic leadership style is 42 people (56.8\%). Performance of nurse executor of majority performing less good as many as 39 people (52.7\%). Bivariate analysis using chi square. The results showed ( $p$ value $=0.731)$. conclusion: there is no correlation between leadership style of head of room to performance of nurse executor in General Hospital dr. Slamet Garut.
\end{abstract}

Key word: leadership styles, head of the room, performance of implementing nurses 


\section{PENDAHULUAN}

Dalam sebuah organisasi keberhasilan suatu organisasi khususnya di rumah sakit tergantung pada berbagai macam sumber daya yang dimilikinya, salah satu sumber daya yang sangat penting yaitu sumber daya manusia (SDM) termasuk di dalamnya perawat.

Kepemimpinan seorang pemimpin sangat mempengaruhi akan keberhasilan sebuah organisasi (Thoha, 2006). Kepemimpinan merupakan seni atau gaya seseorang untuk mengelola, merencanakan, mengarahkan, mengontrol dan memberi inspirasi kepada orang lain untuk dapat bekerja sama agar dapat mencapai suatu tujuan organisasi. Dalam mewujudkan sasaran yang ditetapkan organisasi seorang pemimpin harus memiliki kemampuan dalam menggerakan, membimbing dan mengarahkan orang lain agar tujuan organsisasi dapat tercapai.

Kemampuan memimpin diperoleh melalui pengalaman hidup sehari-hari. Setiap pemimpin memiiliki gaya kepemimpinan yang berbeda-beda untuk menilai staf atau bawahannya satu persatu (Bachtiar,2004). Efektivitas kerja yang optimal dapat tercipta apabila anggotanya bekerja denga baik sesuai harapan organisasi.

Hal ini dapat terjadi apabila gaya kepemimpinan seorang pemimpin sesuai dengan situasi dan kondisi di organisasi (Handoko, T Hani, 2003).

Proses pelayanan keperawatan di rumah sakit khususnya di ruang rawat inap dipimpin oleh seorang kepala ruangan yang bertindak sebagai pelaksana tugas perawat dan membawahi perawat pelaksana lainnya (Soeroso, S, 2003). Kepala ruangan berperan sebagai manajer dan juga berperan sebagai seorang pemimpin (Kuntoro, dan Agus, 2010). Kepala ruangan keperawatan mempunyai wewenang dan tanggung jawab menggerakan, membuat penjadwalan kerja, mengawasi dan melakukan evaluasi terhadap kinerja perawat (Suyanto,2009).

Dalam rangka pencapaian tujuan tugas pokok profesi dan terwujudnya tujuan dan sasaran unit organisasi dalam memberikan asuhan keperawatan seorang perawat dituntut mengimplementasikan sebaik-baiknya suatu wewenang tugas dan tanggung jawabnya sebagai seorang perawat. kinerja para perawat dinyatakan berhasil apabila perawat dapat memberikan pelayanan keperawatan dan asuhan keperawatan dengan baik. (Kuntoro. Agus, 2010). 
Pengkajian, diagnosa, intervensi, implementasi dan evaluasi secara berkesinambungan di berbagai tatanan pelayanan kesehatan yang diberikan dalam upaya memenuhi kebutuhan klien yang optimal merupakan proses atau rangkaian kegiatan pada praktik keperawatan dalam asuhan keperawatan (Nursalam, 2009).

Standar asuhan keperawatan merupakan pedoman yang digunakan perawat dalam memberikan asuhan keperawatan dengan menggunakan pendekatan proses keperawatan yang dilaksanakan oleh perawat umum atau spesialis diseluruh tatanan pelayanan kesehatan. Standar asuhan keperawatan mengacu pada proses keperawatan, yaitu : standar pengkajian, standar diagnosis, standar perencanaan, standar implementasi, standar evaluasi (PPNI,2005).

Peran kepala ruangan bertanggung jawab terhadap hasil dari pelayanan keperawatan yang berkualitas. Kualitas pelayanan keperawatan sangat ditentukan oleh perencanaan yang dibuat oleh kepala ruangan. Dalam menjalankan tugasnya kepala ruangan memiliki fungsi dalam perencanaan baik jangka pendek maupun jangka panjang dan membentuk struktur organisasi.

Berdasarkan survei awal berupa wawancara yang dilaksanakan di Ruang rawat inap RSU dr. Slamet Garut, ditiga ruangan terhadap 10 perawat yang dipilih secara random, diperoleh hasil bahwa beberapa perawat mengatakan jika setiap ada permasalahan, kepala ruangan selalu melakukan musyawarah, mengikut sertakan bawahannya, mendengarkan saran dan masukan-masukan yang berasal dari bawahannya.

Dari hasil wawancara terhadap 3 orang pasien, 1 orang pasien diantaranya mengatakan bahwa perawat memberikan asuhan keperawatan dan tindakan dengan cepat sehingga ada kepuasan bagi pasien terhadap pelayanan kinerja perawat, Menurut penuturan 2 orang pasien lainnya, mengatakan ada beberapa perawat yang kurang rapi, kurang ramah, kurang peduli terhadap kebutuhan pasien. Berdasarkan penuturan yang diperoleh dari kepala ruangan, selama dalam memimpin ruangan dan staf perawat, menemukan beberapa orang staf yang kurang disiplin, misalnya ada yang tidak tidak hadir dan ada pula yang datang terlambat.

\section{METODE PENELITIAN}

Desain penelitian yang digunakan adalah deskriptif korelasi dengan pendekatan yang digunakan yaitu potong lintang (cross sectional). Populasi pada 
penelitian ini adalah semua perawat yang bertugas di ruang rawat inap di ruang rawat inap RSU dr. Slamet Garut yang berjumlah 296 orang. Adapun dalam penelitian ini metode pengambilan sampel yang digunakan adalah Propotional stratified random sampling dengan sampel 74 orang.

Dari hasil Uji validitas pada variabel gaya kepemimpinan kepala ruangan menunjukan hasil bahwa seluruh item pernyataan dinyatakan valid karena corrected item-total correlation > $\mathrm{r}$ table yaitu 0,553 (pada taraf signifikansi 5\%, $\mathrm{n}=15$ ) dan untuk menguji validitas pada variabel kinerja perawat dinyatakan valid karena nilai corrected item-total correlation > r table yaitu 0,553 (pada taraf signifikansi $5 \%, \mathrm{n}=15$ ) yang mana 28 item pertanyaan tersebut dimasukan kedalam kuesioner dan digunakan pada penelitian ini untuk mengetahui kinerja perawat pelaksana.

\section{HASIL DAN PEMBAHASAN}

\section{Hasil Penelitian}

Pada bagian ini peneliti menyajikan hasil penelitian yang sudah dilakukan dengan menggunakan data primer terhadap 74 orang responden mengenai pengaruh gaya kepemimpinan kepala ruangan terhadap kinerja perawatpelaksana di ruang rawat inap RSU dr. Slamet Garut dari bulan AprilMei tahun 2018.

Tabel 1 Distribusi Frekuensi Karakteristik Umur Responden di Ruang Rawat Inap RSU dr. Slamet Garut Tahun 2018

\begin{tabular}{ccc}
\hline Umur (Tahun) & Frekuensi & Persentase (\%) \\
\hline$<34$ & 36 & 48.6 \\
$\geq 34$ & 38 & 51.4 \\
\hline Total & $\mathbf{7 4}$ & $\mathbf{1 0 0}$ \\
\hline
\end{tabular}

Dari Tabel 1 dapat diketahui bahwa sebagian besar $(51,4 \%)$ umur responden adalah berumur $\geq 34$ tahun.

Tabel 2 Distribusi Frekuensi Karakteristik Jenis Kelamin Responden di Ruang Rawat Inap RSU dr. Slamet Garut Tahun 2018

\begin{tabular}{ccc}
\hline Jenis Kelamin & Frekuensi & Persentase (\%) \\
\hline Perempuan & 48 & 64.9 \\
Laki-laki & 26 & 35.1 \\
\hline Total & $\mathbf{7 4}$ & $\mathbf{1 0 0}$ \\
\hline
\end{tabular}

Dari Tabel 2 diketahui bahwa sebagian besar $(64.9 \%)$ jenis kelamin responden adalah perempuan. 
Tabel 3 Distribusi Frekuensi Karakteristik Pendidikan Responden di Ruang Rawat Inap RSU dr. Slamet Garut Tahun 2018

\begin{tabular}{ccc}
\hline Pendidikan & Frekuensi & Persentase (\%) \\
\hline SPK & 3 & 4.1 \\
D3 & 27 & 36.5 \\
S1 & 36 & 48.6 \\
Ners & 8 & 10.8 \\
\hline Total & $\mathbf{7 4}$ & $\mathbf{1 0 0}$ \\
\hline
\end{tabular}

Dari Tabel 3 diketahui bahwa pendidikan responden sebagian besar (48.6\%) berpendidikan S1 keperawatan.

Tabel 4 Distribusi Frekuensi Status Kerja Responden di Ruang Rawat Inap RSU dr. Slamet Garut Tahun 2018

\begin{tabular}{ccc}
\hline Status Kerja & Frekuensi & Persentase (\%) \\
\hline TKK & 34 & 45.9 \\
PNS & 40 & 54.1 \\
\hline Total & $\mathbf{7 4}$ & $\mathbf{1 0 0}$ \\
\hline
\end{tabular}

Dari tabel 4 diketahui bahwa status kerja responden sebagian besar $(54.1 \%)$ adalah PNS.

Tabel 5 Distribusi Frekuensi Lama Kerja Responden di Ruang Rawat Inap RSU dr. Slamet Garut Tahun 2018

\begin{tabular}{ccc}
\hline Lama Kerja & Frekuensi & Persentase (\%) \\
\hline$<9$ & 35 & 47.3 \\
$\geq 9$ & 39 & 52.7 \\
\hline Total & $\mathbf{7 4}$ & $\mathbf{1 0 0}$ \\
\hline
\end{tabular}

Dari Tabel 5 dapat diketahui bahwa sebagian besar (52.7\%) lama kerja adalah yang $\geq 9$ tahun.

Tabel 6 Distribusi Frekuensi Gaya Kepemimpinan di Ruang Rawat Inap RSU dr. Slamet Garut Tahun 2018

\begin{tabular}{lcc}
\hline Gaya Kepemimpinan & Frekuensi & $\begin{array}{c}\text { Persentase } \\
(\mathbf{\%})\end{array}$ \\
\hline Otokratis & 19 & 25.7 \\
Demokratis & 42 & 56.8 \\
Laissez Fire & 13 & 17.6 \\
\hline Total & $\mathbf{7 4}$ & $\mathbf{1 0 0}$ \\
\hline
\end{tabular}

Hasil analisis Tabel 6 di atas menunjukan bahwa sebagian besar $(56.8 \%)$ responden menilai bahwa gaya kepemimpinan kepala ruangan di ruang rawat inap RSU dr. Slamet Garut bergaya demokratis.

Tabel 7 Distribusi Frekuensi Kinerja Perawat Pelaksana di Ruang Rawat Inap RSU dr. Slamet Garut Tahun 2018

\begin{tabular}{ccc}
\hline Kinerja Perawat & Frekuensi & Persentase (\%) \\
\hline Baik & 35 & 47.3 \\
Kurang baik & 39 & 52.7 \\
\hline Total & $\mathbf{7 4}$ & $\mathbf{1 0 0}$ \\
\hline
\end{tabular}


Hasil analisis Tabel 7 di atas menunjukan bahwa proporsi kinerja perawat pelaksana sebagian besar $(52.7 \%)$ memiliki kinerja yang kurang baik.

Tabel 8 Pengaruh Gaya Kepemimpinan Kepala Ruangan terhadap Kinerja Perawat Pelaksana di Ruang Rawat Inap RSU dr. Slamet Garut 2018

\begin{tabular}{|c|c|c|c|c|c|}
\hline \multirow{3}{*}{$\begin{array}{c}\text { Gaya } \\
\text { Kepemimpinan }\end{array}$} & \multicolumn{4}{|c|}{$\begin{array}{c}\text { Kinerja Perawat } \\
\text { Pelaksana }\end{array}$} & \multirow{3}{*}{ P. Value } \\
\hline & \multicolumn{2}{|c|}{ Baik } & \multicolumn{2}{|c|}{ Kurang } & \\
\hline & $\mathbf{F}$ & $\%$ & $\mathbf{F}$ & $\%$ & \\
\hline Otokratis & 10 & 13.5 & 9 & 12.2 & \\
\hline Demokratis & 20 & 27.0 & 22 & 29.7 & \\
\hline Laissez Fire & 5 & 6.8 & 8 & 10.8 & 0.731 \\
\hline Total & 35 & 47.3 & 39 & 52.7 & \\
\hline
\end{tabular}

Hasil analisis Tabel 8 diatas menunjukan bahwa $(25.7 \%)$ perawat menilai gaya kepemimpinan kepala ruangan di ruang rawat inap RSU dr. Slamet Garut adalah otokratis yang diantaranya (13.5\%) memiliki kategori kinerja baik, (12.2\%) kategori kinerja kurang baik, (56.8\%) perawat menilai gaya kepemimpinan kepala ruangan di ruang rawat inap yaitu demokratis yang mana (27\%) memiliki kinerja baik, $(29.7 \%)$ berkinerja kurang baik.
Sedangkan (17.6\%) perawat menilai gaya kepemimpinan kepala ruangan di ruang rawat inap adalah laissez fire dengan $(47.3 \%)$ kategori kinerja baik dan untuk $(10.8 \%)$ berkinerja kurang baik. Berdasarkan hasil uji statistik diperoleh PValue $=0.731$ karena P-Value $\leq \alpha(0,05)$, maka Ho diterima, sehingga dapat ditarik kesimpulan gaya kepemimpinan kepala ruangan tidak mempengaruhi terhadap kinerja perawat pelaksana.

\section{Pembahasan}

\section{a. Gaya Kepemimpinan Kepala Ruangan}

Proses pelayanan keperawatan di rumah sakit khususnya di ruang rawat inap dipimpin oleh seorang kepala ruangan yang bertindak sebagai pelaksana tugas perawat dan membawahi perawat pelaksana (Soeroso, S, 2003).

Dalam menjalankan tugasnya kepala ruangan memiliki gaya kepemimpinan tersendiri dalam memimpin. Dalam mencapai tujuan organisasi seorang pemimpin mampu menentukan gaya kepemimpinan sesuai 
situasi dan kondis yang ada didalam organisasi.

Untuk menyamakan persepi antara tujuan individu dengan tujuan organisasi. untuk mencapai suatu tujuan. Gaya tersebut dapat digunakan oleh pemimpin untuk menilai kinerja staf atau bawahannya satu persatu (Bachtiar, 2004).

Terpenuhinya kebutuhan anggota oleh gaya kepemimpinan kepala ruangan yang sesuai dengan situasi dan kondisi organisasi dapat membantu menciptakan efektivitas kerja yang positif dan memberikan semangat bagi anggota dalam organisasi (Handoko, T Hani, 2003).

Hasil penelitian yang dilakukan di Ruang rawat inap RSU dr. Slamet Garut dari 74 responden yang diteliti diketahui bahwa gaya kepemimpinan kepala ruangan sebagian besar bergaya kepemimpinan demokratis $(56.8 \%)$, sedangkan sisanya memiliki gaya kepemimpinan otokratis (25.7\%), dan laissez fie (17.6\%). Hasil penelitian ini sejalan dengan penelitian yang dilakukan oleh Mamonto, dkk (2013) yang menyatakan bahwa sebagian besar responden memilih gaya demokratis $(84.9 \%)$ dan sisanya memilih gaya Otokratis $(15.1 \%)$ dan tidak ada yang memilih gaya laissez fire.
Hasil yang sama diperoleh dari penelitian yang dilakukan oleh Hardiansyah (2013) tentang hubungan gaya kepemimpinan kepala ruangan dengan motivasi kerja perawat yang menunjukan sebagian besar responden memilih terhadap gaya kepemimpinan demokratis.

Ciri kepemimpinan demokratis yaitu: dalam pengambilan keputusan pemimpin tidak mengambil keputusan secara sepihak akan tetapi mau mendengarkan saran dan masukan bawahan. Seorang pemimpin yang demokratis menganggap bawahannya sebagai pribadi yang dapat mengerjakan dan menyelesaikan pekerjaan dengan baik serta mandiri. Hubungan antara pimpinan dan bawahan bersifat professional baik sebagai atasan dengan bawahan ataupun sebagai rekan kerja atau relasi (Swanburg, 2001).

\section{Perawat pelaksana lainnya} mempersepsikan gaya kepemimpinan kepala ruangan di instalasi rawat inap penyakit dalam adalah otoriter/ autokratis berdasarkan hasil penelitian dalam hal pengambilan keputusan, wewenang dan perencanaan selalu bersifat satu arah, bawahan dipandang 
belum matang/dewasa, kebutuhan bawahan kurang diperhatikan dan pelaksanaan tugas didasarkan adanya ketakutan, ancaman dan sanksi (Swanburg, 2001).

Hasil penelitian tidak didapatkan orang yang mempersepsikan gaya kepemimpinan kepala ruangan termasuk tipe Liberal/Laissez faire.

\section{b. Kinerja Perawat Pelaksana}

Berdasarkan hasil penelitian ini didapatkan bahwa sebagian besar perawat dengan kinerja kurang baik sebanyak $(52.7 \%)$ dan sisanya $(47.3 \%)$ perawat dengan kinerja baik. Hal ini menunjukan bahwa mayoritas perawat pelaksana di Ruang rawat inap RSU dr. Slamet Garut mempunyai kinerja kurang baik. Hasil penelitian ini sejalan dengan hasil penelitian Rohayani (2007) yang menyataan bahwa sebagian perawat mempersepsikan kinerjanya kurang baik $(56,6 \%)$ dan sisanya sebanyak $(43,4 \%)$ mempersepsikan kinerjanya baik.

Mayoritas perawat pelaksana di Ruang rawat inap RSU dr. Slamet Garut memiliki kemampuan dan motivasi yang kurang baik dalam melaksanakan tugas-tugas asuhan keperawatan.
Sebagai bagian dari fungsi pengawasan, evaluasi dan kontroling kerja perawat diperlukan penilaian kerja bagi perawat sebagai umpan balik dalam pencapaian kinerja perawat.

\section{c. Hubungan Gaya Kepemimpinan} Kepala Ruangan Terhadap Kinerja

\section{Perawat Pelaksana}

Hasil penelitian menunjukan bahwa tidak ada pengaruh gaya kepemimpinan kepala ruangan terhadap kinerja perawat pelaksana di Ruang rawat inap RSU dr. Slamet Garut. Hasil ini tidak sejalan dengan hasil penelitian hal ini terlihat dari nilai $p$-value yang lebih besar dari $\alpha(0.05)$ yaitu 0.731 .

Peran kepala ruangan selain membuat perencanaan kerja, memberikan arahan dan motivasi kerja juga mengawasi pegawai guna mencapai tujuan organisasi (Perceka, Andhika Lungguh, 2017). Salah satu faktor yang mempengaruhi kinerja adalah pengawasan dari pimpinan (Nursalam, 2002). Oleh itu agar tujuan organisasi dapat tercapai diperlukan sebuah sistem penilaian kerja perawat, melalui evaluasi kerja yang berkesinambungan. 


\section{KESIMPULAN DAN SARAN}

\section{Kesimpulan}

Hasil penelitian tentang Pengaruh gaya kepemimpinan kepala ruangan dengan kinerja perawat pelaksana ruang rawat inap di Rumah Sakit Umum Daerah dr. Slamet Garut Tahun 2018 dapat disimpulkan sebagai berikut:

a. Gaya kepemimpinan kepala ruangan di ruang rawat inap di Rumah Sakit Umum Daerah dr. Slamet Garut Tahun 2018 sebagian besar bergaya kepemimpinan demokratis.

b. Kinerja perawat pelaksana ruang rawat inap di Rumah Sakit Umum Daerah dr. Slamet Garut Tahun 2018 Sebagian besar berada pada kategori kinerja kurang baik.

c. Gaya kepemimpinan kepala ruangan tidak mempengaruhi kinerja perawat pelaksana ruang rawat inap di Rumah Sakit Umum Daerah dr. Slamet Garut Tahun 2018.

\section{Saran}

Berdasarkan kesimpulan penelitian ini, maka peneliti memberikan beberapa saran sebagai berikut :

\section{a. Bagi Institusi Pendidikan}

Sebagai masukan dalam proses belajar mengajar tentang gaya kepemimpinan kepala ruangan terhadap kinerja perawat pelaksana, sehingga mahasiswa mendapat informasi yang jelas.

b. Bagi Instasi RSUD dr Slamet Garut Bagi rumah sakit diharapkan menjadi masukan agar lebih memperhatikan faktor lain selain gaya kepemimpinan yang dapat mempengaruhi kinerja perawat pelaksana, seperti halnya imbalan, sikap, motivasi, kepribadian, kemampuan, disiplin dll.

\section{c. Bagi peneliti selanjutnya}

Bagi peneliti selanjutnya, perlu dilihat faktor lain yang dapat mempengaruhi kinerja perawat pelaksana, diharapkan melakukan penelitian lanjut tentang gaya kepemimpinan dengan metode berbeda, misal dengan penelitian kualitatif tentang gaya kepemimpinan dan kinerja perawat pelaksana.

1 STIKes Karsa Husada Garut 


\section{DAFTAR PUSTAKA}

Bachtiar. (2004). Manajemen Sukses : Kiat Menghadapi Enam Hal yang Mengganggu Sukses Anda. Jogjakarta: Saujana Jogjakarta

Gillies, D. A. (1996). Manajemen Keperawatan: Suatu Pendekatan Sistem. Penerjemah: Dika. Philadelphia: W.B Sauders Company

Handoko, T. Hani. (2003). Manajemen. Yogyakarta: BPFE

Hardiasyah. (2013). Hubungan antara Pemberian Kompensasi, Gaya Kepemimpinan dan Sarana-Prasarana dengan Motivasi Kerja Cleaning Service di RSUP Prof. Dr. R.D. Kandou. Melalui <https://ejournal health.com/index.php/CH/article/view File/182/176> Tanggal [15-05-18]

Kuntoro, Agus. (2010). Buku Ajar Manajemen Keperawatan. Yogyakarta: Nuha Medika

Marquis \& Houston. (2000). Management Decision Making for Nurses. Philadelphia : Lippincott

Mamonto. (2013). Hubungan Gaya Kepemimpinan Kepala Ruangan dengan Tingkat Stres Kerja Perawat di Ruang Rawat Inap RSUD Bitung. Melalui <http//ejournal. Unsrat.ac.id/ index > pada Tanggal [27/05/2018]

Nursalam. (2002). Manajemen Keperawatan: Aplikasi dalam Praktik Keperawatan Profesional. Jakarta: Salemba Medika.
(2009). Manajemen Keperawatan

Aplikasi dalam Praktik Keperawatan Profesional. Jakarta: Salemba Medika

PPNI. (2005). Standar Asuhan Praktik Keperawatan. Melalui <http://www.ob servatorisindonesia.org/wp-content/up loads/2014/09/14-standarpraktik-Kep_ Standard-of-Nursing-Practice.pdf pada Tanggal [15-05-18]

Potter \& Perry. (2005). Buku Ajar Fundamental Keperawatan. Jakarta: EGC

Rohayani. (2007). Hubungan Persepsi Perawat Pelaksana tentang Gaya Kepemimpinan Kepala Ruangan dengan Kinerja Perawat Pelaksana. Melalui <https//:jurnal.unimus.ac.id> pada Tanggal [24/05/2018]

Santoso, Soeroso. (2003). Manajemen Sumber Daya Manusia di Rumah Sakit. Jakarta : EGC

Suyanto. (2009). Mengenal Kepemimpinan dan Manajemen Keperawatan di Rumah Sakit. Jogjakarta : Mitra Cendikia Press

Siagian, S.P. (2002). Fungsi-Fungsi Manajerial. Jakarta : Bumi Aksra

Soeroso, S. (2003). Manajemen Sumber Daya Manusia di Rumah Sakit. Jakarta: ECG

Swansburg, R. C. (2001). Pengembangan Staf Keperawatan : Suatu Komponen Pengembangan SDM. Cetakan I. Jakarta: EGC 
Suyanto. (2009). Mengenal Kepemimpinan dan Manajemen Keperawatan di Rumah Sakit. Jogjakarta : Mitra Cendikia Press

Thoha. (2006). Kepemimpinan dalam Manajemen. Jakarta : PT. Raja Grafindo Persada 